\title{
To Prevent 'Panic' in an Underground Emergency: Why Not Tell People the Truth?
}

\author{
GUYLENE PROULX \\ Université de Montreal \\ Faculté de l'Aménagement \\ C.P. 6128, Succursale A, Montréal, Québec H3C 3J7, Canada
}

JONATHAN D. SIME

Jonathan Sime Associates

26 Croft Road, Godalming, Surrey GU7 2BY, UK

\begin{abstract}
The research study reported was carried out on behalf of Tyne and Wear Passenger Transport Executive (P.T.E) in Newcastle U.K., in order to assess the efficiency of their communication system in the event of an emergency evacuation. There were two stages in the research programme. Firstly, an evaluation of the day to day functioning of the sub-surface stations as an information system was carried out with particular reference to way finding. Secondly, an experiment involving five evacuations was conducted in the most spatially complex station. The information given to users in each of the five evacuations differed: 1 . alarm bell only, 2 . alarm bell with two staff members, 3 . alarm bell and minimal non-directive public announcements, 4 . alarm bell with two staff members and directive public announcements, 5 , alarm bell with improved directive public announcements. Three measures were assessed: the time to start to move, the time to clear the station and the appropriate behaviour in the situation. The results show that evacuations 4 and 5 were completed rapidly and safely. The study highlights the importance of issuing prompt instructions to the public, explaining what is happening, what to do and why, if a successful evacuation is to be achieved.
\end{abstract}

KEYWORDS: 'panic', underground station, fire, information, communications, time to start, alarm bell, Control Room, CCTV, Public Address (P.A.)

\section{INTRODUCTION}

Traditionally managers of public buildings have considered that in the event of an emergency it is better not to tell people the truth if panic is to be avoided. This belief has been translated into safety procedures which in disasters have characteristically witheld information about a threat of a fire from the public beyond the point when escape has been possible. Many public buildings are now equipped with communication systems such as closed circuit television (CCTV) monitoring cameras, visual display screens and public address speakers, which could be used to organise an evacuation. Unfortunately, the significant contribution these advances in technology could make in communicating with the public in complex building settings is insufficiently recognised. Even if a public announcement system exists, many safety managers of public places still prefer not to use a Public Address (P.A.) to give out early warnings to the public. Instead, staff members, who are not always well prepared for emergency tasks, have been expected to control the incident and efficiently evacuate the building if necessary. It is argued in this paper that, rather than avoiding 'panic', a delay in warning the public is self-fulfilling. When an incident such as a fire gets out of hand, the delay is paradoxically a major determinant of flight behaviour, crushing and deaths in major crowd disasters. 
The last two decades have produced a rich body of research on human behaviour in emergency situations, which has not been absorbed properly into evacuation planning and fire safety engineering. One of the most important findings, which earlier sociological and psychological research had pointed to, is the rejection of the concept of 'panic' [1]. For a long time, it has been common practice in the media to depict those who die in fires as victims of their own propensity for 'panic' or irrational and egocentric flight behaviour, resulting in crushing at an exit. Far from being 'evidence' of irrational panic behaviour, as is often assumed by the public and those who might otherwise have to accept responsibility for the deaths, interviews with large numbers of victims show that panic rarely occurs and in any case is difficult to operationally measure $[1,2]$. If one judges behaviour in fires from the perspective of the survivors and by inference those who die in extreme situations, it is clear that far from being 'irrational', behaviour such as fleeing to a familiar building entrance is what most people would 'rationally' do if faced by an objective threat [3].

If people do not panic in an emergency situation, but act in accordance with their knowledge of a setting and situation, and if they need information to define the situation and to take the decision to evacuate, fire safety design codes and evacuation management guidance should pay greater attention to the relationship between warning systems and overall evacuation times. In this respect design parameters such as exit width and travel distance, which have been equated traditionally with predicted escape times, are less likely to be related to overall evacuation times than is the time for people to start to move to safety [4]. If people take a long time to start to evacuate a setting the residual time to reach safety can be dramatically reduced. A number of researchers have suggested that alarm bells are likely to be less effective than a vocal alarm and/or visual display information system in initiating prompt and appropriate action [5,6,7]. Unfortunately, a limited number of research studies have actually examined the relationship between different forms of information system, evacuation management strategies through alternative communications and evacuation times. It is in this context that the present study was devised.

\section{FIRE SAFETY IN UNDERGROUND SPACES}

In the past few years dramatic disasters in the U.K., such as King's Cross, Bradford and Hillsbrough, have demonstrated that safety management needs to be rethought if efficient evacuations of public settings are to be achieved. Fire safety procedures, although well planned and organised, should be regularly tested to ensure their feasibility. The Tyne and Wear Metro Passenger Transport Executive on the advice of the Tyne and Wear Metropolitan Fire Brigade, commissioned a research study to assess their communication system in relation to safety criteria set out in the Fire Precautions (Sub-surface Railway Stations) Regulations 1989: in particular, clause 4 of Regulation 10 , which requires '...that not less than two persons are present on duty in the premises at all times when members of the public have access to the premises'. These regulations also require in clause 6 of Regulation 6, that station premises shall be provided with a Public Address (P.A.) system, but make no reference to a CCTV system of surveillance cameras, Control Centre and P.A. system linked to a Control Centre.

\section{TYNE AND WEAR METRO}

The Tyne and Wear Metro is a light rail urban transport system located in Newcastle upon Tyne U.K. The network comprises 44 stations including 10 sub-surface stations distributed along four Metro lines. The system has been developed since 1980 and currently transports around 200,000 passengers per day. Tyne and Wear Metro has a self-service ticketing system with turnstiles at Concourse level to delimit the 'valid ticket area'. There are no permanent staff members on stations. Revenue Control Inspectors (RCIs) patrol the Metro system checking tickets, disseminating information and helping with any problem. Passengers can obtain information about routes and tickets at the four Travel Centres located in the main sub-surface stations or plan their journey by themselves relying on 'Information boards' and various graphic displays. They can also use the 'Information Point' located on each platform and Concourse to communicate with Station Controllers. 
The Control Centre building where the Control Room is located is the nerve centre of the system. The Control Room is active 24 hours a day and comprises Train Controllers and Station Controllers. The duty of Train Controllers is to supervise a safe and efficient train service. They are in direct contact through a radio system with all train drivers on the Metro, who in turn can give messages to their train passengers.

Station Controllers are responsible for station technical operations, and passenger information and safety. Detection of any technical fault in a station is transmitted to a computer which alerts the Station Controllers who dispatch the information to appropriate technicians. From cameras located in each station they monitor through CCTV screens the activities on the sub-surface stations. A public announcement system allows Station Controllers to give messages to specific areas of a station, within a whole station or to the entire system. The coupling of computer, cameras and public announcement system gives the Station Controllers an overview of the activities on a station and the possibility of giving users precise messages.

Each station also has a local public announcement system which can be used by staff members to inform the station users of any problem. Next to this communication system is an electronic board to be consulted by staff and firemen which displays the location of technical faults occurring on the station.

\section{TESTING THE COMMUNICATION SYSTEM}

The communication system in an environment comprises information coming from different sources. The architecture and interior design convey information. Members of staff give verbal information personally or through public announcements. Signs, maps and diagrams also convey information. All of these elements should be organised in an interactive fashion to create a broad Communication System.

A two stage User Safety Evaluation procedure was developed to test the actual relationship between the existing Tyne and Wear communication system and the efficient evacuation of the sub-surface stations. Stage 1 consisted of an assessment of the day to day use of the stations with particular reference to sources of information used in people finding their way through the system [8]. If problems exist in the daily use of a public space, these problems are likely to be compounded when a sub-surface station is evacuated in an emergency. An appraisal of the daily use of a building can be critically important and should precede any attempt to develop safety strategies.

The second stage of the study consisted of an experiment to measure the efficiency in evacuating a sub-surface station when the procedures and information given to users was systematically varied [9]. In this respect, the independent variables were variations in communications and the dependant variables or measures the reponses of the public. A specific purpose of Stage 2 was to compare the efficiency of an emergency evacuation with two members of staff present on the station and a local P.A. system available with a communications system based on a Control Room giving out directive P.A. messages. A secondary aim of Stage 2 was to appraise the evacuation planning, training, communications, staffing and operational coordination of communications and staff responsibilities during potential emergencies.

\section{APPRAISAL OF THE DAILY USE OF THE SUB-SURFACE STATIONS}

The appraisal of the use of the sub-surface stations [8], described step by step the journey of a user from the entrance to a station, down to the platforms and then, from arrival on a train back up to ground level and out of the stations. Components evaluated were of different orders: the architecture, information and organisation. The architectural features of a station comprise the legibility of the access and exit, distinction between public space and passenger space, accessibility to means for horizontal and vertical movement. The information available was judged for its location, quality, quantity and relevance in taking decisions. Finally, the organisation and functioning of the 
setting was assessed. The appraisal compared the system as planned by its managers with the way it is actually used in reality.

Observations were made of people's behaviour and passengers and staff were also asked specific questions about the use of the system. In the limited time available for the Stage 1 appraisal, the researchers concentrated on appraising of the use of the space in relation to principles derived from previous design research on 'wayfinding' in complex spaces such as underground systems [10]. The primary emphasis in this research has been on the perspective of the majority of a setting's users, the public. In this respect, if users assess a space as badly organised, if they tend to get lost and the information given is judged unsatisfactory, their confidence about the efficiency of the organisation and management could be low. This would compromise any attempt to organise a safe evacuation (for example, undermining the credibility of P.A. messages during an emergency).

\section{RESULTS OF STAGE 1}

The appraisal gave a general portrait of the use and functioning of the sub-surface stations. The analysis showed that the Metro has the excellent qualities of simplicity, coherence and reliability. The legibility of the architecture and interior design as well as the straightforward organisation of a majority of stations facilitates smooth circulation in the stations. The sign system is generally consistent and information is provided at decision points. However, passengers unfamiliar with the Metro have difficulty in understanding the ticketing system and using the self-service ticket machine. Once the ticket is bought what to do with it becomes another problem; turnstiles seem to infer that tickets must be slipped into the machine some where when in fact turnstiles are only for crowd control.

The absence of a name for different areas such as staircases, escalators and platforms within a station, makes it difficult sometimes to give directions to people or to receive them. Another difficulty arises for unfamiliar users because trains for different destinations can stop at the same platform, and a user could take the wrong train if the destination is not checked.

All Metro stations are accessible. Entrances are mostly level with the street and a lift is located at the Concourse to go down to platforms. This ease of accessibility accommodates a large proportion of passengers daily who are elderly, people with pushchairs, trolleys and wheelchair users. For example, an average of 15 pushchairs were counted passing in and out at Monument station for periods of 10 minutes observed during day time. As individuals with mobility difficulties, and accompanying social groups, represent a significant proportion of the regular users of the Metro, this means that this should be taken into account in the planning of evacuation procedures in the event of an emergency.

\section{EVACUATION STUDY}

On the basis of Stage 1 and after detailed discussion with the Fire Brigade and the PTE, a central station was chosen for the execution of Stage 2. Monument is the busiest station on the system and is probably the most spatially complex with; three entrances, three underground levels, four platforms, two sets of three escalators and a staircase (see Fig.1). An advantage of Monument station in terms of extrapolating from an evacuation study to an actual fire, is its spatial organisation which in a simplified form resembles King's Cross station in London. Although on a smaller scale, Monument has two sets of escalators leading up to the circular Concourse; if one set of escalators is blocked it is possible to use the staircase as an alternative route to get to the other set of escalators.

To test the safety communication procedures and information sytem a 'fire scenario' was planned. Because of the similarity in layout to King's Cross, the decision was taken to 'locate the fire' on the North/South escalators of Monument station (equivalent to the Piccadilly line set of escalators at King's Cross). The alternative E/W escalators would be equivalent to the Victoria line escalators at King's Cross in the fire scenario. Members of the public were directed by transport police officers up the Victoria escalator to the ticket hall Concourse where they were caught by the 


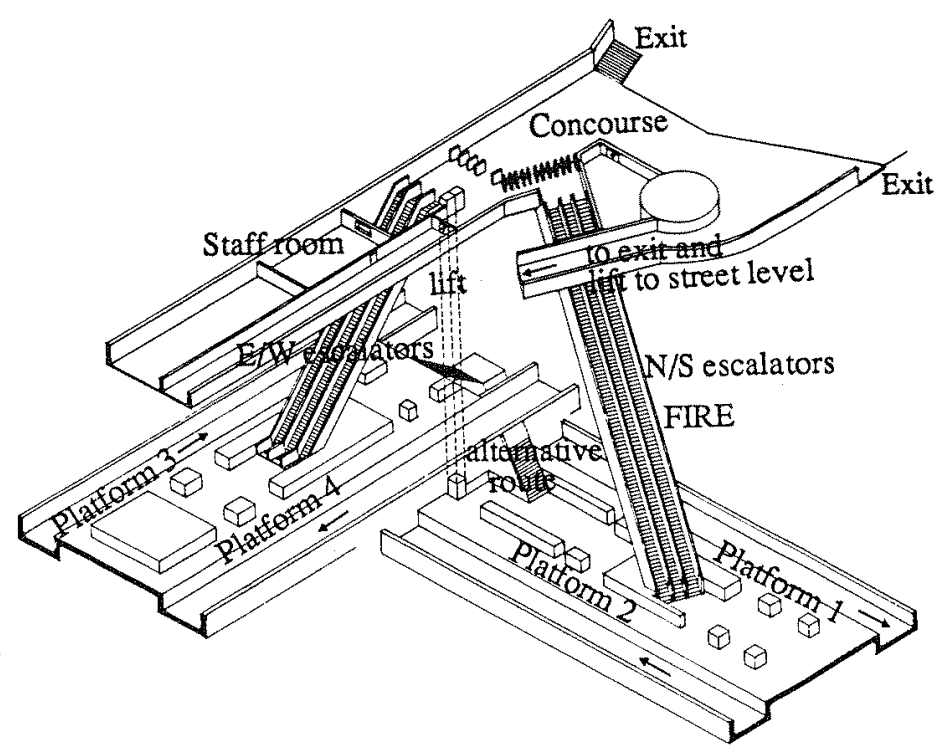

fire which suddenly spread from the Piccadilly line escalator. 31 people died in the Concourse area. The Inquiry report on the King's Cross fire explains the movement of smoke and fire which provided the framework for developing the scenario used in the Metro evacuations [11].

\section{FIVE EVACUATION PROCEDURES}

The fire scenario was consistent throughout the five evacuation exercises; only the staffing provision and the information given to users was systematically varied in the different evacuations. Evacuations were conducted on five week days at around mid-day (the alarm being set off shortly after 12:18 or 14:18). Previous surveys by the Metro of passenger numbers suggested that there would be a reasonably consistent number of users in the station at around these times. Twelve CCTV cameras were in positions in Monument station which readily permitted monitoring and checking of the scene from the Control Room. Seven observers were posted in positions on the station where cameras did not entirely cover the space. Each observer counted the users going in and out via an entrance/exit or up and down the stairs/escalators using a hand-held taperecorder, potentially allowing measures of passenger frequency and flow rates. During each exercise the N/S and E/W escalators each had two escalators running in an 'Up' direction and one running 'Down'. After each exercise the observers interviewed users with a questionnaire.

The starting time for each exercise was synchronised with the train schedule to ensure that the timing of the first train to arrive at Monument with disembarking passengers would be similar for the five evacuations. The moment train 124 left Haymarket station a call was put through from the Control Room alerting two technicians standing underneath the N/S escalator at Monument, who activated the smoke detector; this simultaneously sounded the fire bell and lit the 'Fire do not enter' signs located at the three entrances and at the top of the two sets of escalators. Four fireman in their uniforms appeared from the staff room and took up their positions, two at the top of the N/S escalators and two at the bottom. The firemen turned off the escalators and prevented people from passing, limiting their instruction to 'evacuate the station'. Five seconds after train 124 arrived on platform 1 at Monument, one of the following five experimental evacuation procedures was initiated: 
Evacuation 1: (Evac 1) The alarm bell was rung; there were no staff on the station and no public address (P.A.) announcement given.

Evacuation 2: (Evac 2) Two staff members (RCI) who knew there was to be a fire drill stood waiting on platform 3. When they heard the fire bell, they contacted the Control Room for information using the emergency button on their radio. They were instructed to check the location of the smoke detector activated on the electronic board, to give a public announcement to 'evacuate the station' through the local P.A. system, and to direct the evacuation of all passengers.

Evacuation 3: (Evac 3) Each 30 seconds (ie $10 \mathrm{sec}$ message with 20 secs interval) after the arrival of train 124, the Control Room issued this P.A. 'Please, evacuate the station immediately. Please evacuate the station immediately'. This was equivalent to a prerecorded repeated evacuation message which was minimal or non-directive in its message content. No staff members were present on the station.

Evacuation 4: (Evac 4) Two RCIs and the Control Room in full operation conducted the evacuation following the Metro's normal procedures. The Control Room issued 'directive' P.A.s telling passengers on platforms to board trains and the ones on the Concourse to leave by exits. The RCIs assisted the evacuation in accordance with the P.A.s from the Control Room.

Evacuation 5: (Evac 5) The Control Room was in full operation and issued'directive' P.A.s; no members of staff were present on the station. The P.A.s during Evac 5 were different from Evac 4 because information was given to the users about the incident: the type of incident, its location and what was expected of them. The first P.A. wording was; 'To all passengers. There is a suspected fire on the North/South escalator between the Concourse and platform 1 and 2. Passengers on all platforms should board the first available train. Passengers at Concourse level should leave by the nearest exit. Do not use the lift.' (repeated).

During each exercise the first train arriving at each platform received no specific information. The train driver of each of the subsequent trains received a call from the Train Controller, when the train arrived at a station preceding Monument, which instructed them to give out the following P.A. to the passengers 'Do not disembark at Monument. The train will stop only to pick up passengers'. Four to five minutes after the beginning of the exercise, the Fire Brigade (F.B.) was called. When the FB arrived (ie the fully operational firemen as opposed to the four firemen who 'defined the fire' on the N/S escalators), they checked the location of the suspected fire, helped to evacuate passengers and eventually gave the 'All Clear' signal by resetting the electronic board that cut the alarm bell and 'Fire' signs. At this point the exercise was over.

\section{RESULTS OF STAGE 2}

The analysis of the five evacuations was carried out on three sources of data: observers counting people passing using the tape recorder, video recording from the twelve cameras located in the station and 133 questionnaires completed by evacuees. Three measures were adopted: the time to start to move, the time to clear the station and the objective appropriateness of the behaviour in terms of the potential risk to people (in contrast to the subjective appropriateness of the behaviour in terms of the perceived risk and information available to the staff and public about a danger and the most effective course of action).

Table 1 indicates the elapsed time in minutes from the alarm bell first sounding for people to start to move, to clear the station and the behaviour of the users which was most crucial and characteristic of each evacuation in terms of appropriateness. The time to start to move was measured for two locations on the station where a crowd tended to gather. The open large space on the Concourse level just before the turnstiles is a location where people gathered during each evacuation. The two firemen at the top of the N/S escalators and the 'Fire do not enter' sign generally stopped people from advancing past the turnstiles. At the bottom of the N/S escalators a crowd also gathered, the firemen blocking the way up the escalators which were the the familiar route from platform 1 
and 2 to the Concourse. The time when people started to move was calculated from the video recording when half or more of the immobile crowd started to move. The time to clear the station was the moment when no-one could be seen standing on the platforms, near the escalators or on the Concourse level.

TABLE 1. Times and movement for the 5 evacuations (in mins:secs)

\begin{tabular}{|c|c|c|c|c|}
\hline \multirow[b]{2}{*}{ Evacuation } & \multicolumn{2}{|c|}{ Time to start to move } & \multirow{2}{*}{$\begin{array}{l}\text { Time to clear the } \\
\text { station }\end{array}$} & \multirow{2}{*}{$\begin{array}{l}\text { Appropriateness of } \\
\text { behaviour }\end{array}$} \\
\hline & Concourse & $\begin{array}{l}\text { Bottom } \\
\text { escalator }\end{array}$ & & \\
\hline $\begin{array}{l}1 \\
\text { Bell only }\end{array}$ & $8: 15$ & $9: 00$ & Exercise ended $14: 47$ & $\begin{array}{c}\text { Delayed or no } \\
\text { evacuation }\end{array}$ \\
\hline $\begin{array}{l}2 \\
\text { Staff } \\
\end{array}$ & $2: 15$ & $3: 00$ & $8: 00$ & $\begin{array}{c}\text { Users directed to } \\
\text { Concourse }\end{array}$ \\
\hline $\begin{array}{l}\text { 3 } \\
\text { P.A. }\end{array}$ & $1: 15$ & $7: 40$ & $10: 30$ & $\begin{array}{l}\text { Users stood at bottom } \\
\text { of escalator }\end{array}$ \\
\hline $\begin{array}{l}4 \\
\text { Staff }+ \text { P.A.+ }\end{array}$ & $1: 15$ & $1: 30$ & $6: 45$ & Users evacuated \\
\hline $\begin{array}{l}5 \\
\text { P.A.++ } \\
\end{array}$ & $1: 30$ & $1: 00$ & $5: 45(10: 15)$ & $\begin{array}{l}\text { Users evacuated by } \\
\text { trains and exits }\end{array}$ \\
\hline
\end{tabular}

The appropriate behaviour for the situation was to evacuate the station. If passengers did not take the first train, waited at the bottom of the escalators or on the Concourse, this behaviour was assessed as objectively 'inappropriate'. People at the platform 1 and 2 level such as those located at the bottom of N/S escalators could evacuate via the Concourse by using the alternative route, which meant walking along platform 1 or 2 , going up the staircase, then along platform 3 or 4 to the E/W escalators and ascending to the Concourse (see Fig. 1). Those on the platform 3 and 4 level could similarly use the E/W escalators to reach the Concourse. However, the development of the King's Cross disaster, in which the fire on the Piccadilly escalators filled the concourse with heat, flames, thick black smoke and a flash over occurred, strongly suggested that evacuation from below via the $\mathrm{E} / \mathrm{W}$ escalators would be the most dangerous evacuation route to use in the circumstances (ie if there had really been a fire on the N/S escalators). The appropriate evacuation behaviour in the circumstances of the fire scenario was for people on the lower levels to leave by the next train and for those on the Concourse to leave by the nearest exit from the station.

In Evac 1 (alarm bell only) the time to start to move was very long. In fact a crowd of 66 people at the Concourse level did not start to move until 8:15 mins after the alarm first sounded when the FB arrived and told them to leave. The same thing happened at the bottom of the escalators; the crowd of 45 people started to move at 9:00 mins when the FB arrived and instructed them to leave. The station was never totally cleared. Passengers continued to get off trains and enter the Concourse from outside the station until the alarm was turned off 14:47 mins later. Of the 29 evacuees interviewed, $26(93 \%)$ said they heard the alarm bells, but $19(76 \%)$ thought it wasn't a real emergency. Asked about what they thought they should do when hearing the alarm, $12(48 \%)$ said leave by exits, 6 $(24 \%)$ wait/look for more information, $2(8 \%)$ board a train, and $5(20 \%)$ other non-emergency related actions.

In Evac.2 (Staff), the time to start to move was much quicker. A crowd of 30 people started to evacuate the Concourse 2:15 mins after the onset of the alarm, when one $\mathrm{RCI}$ racing back from the electronic board shouted at them to leave the station. One RCI stayed at Concourse level to give a P.A. using the local system and then prevented people from coming in, and explained to the FB upon their arrival where the suspected fire was located. The other RCI took charge on the platforms levels. This RCI initiated the movement of 53 people standing at the bottom of the escalator 3:00 mins after 
the alarm. All passengers at the bottom of the $\mathrm{N} / \mathrm{S}$ escalators and on platforms 1 and 2 , were directed through the alternative route to the Concourse. The same thing happened to passengers on platforms 3 and 4. The Station was clear after 8:00 mins. Of the 31 evacuees interviewed, $28(90 \%)$ said they heard the alarm and $22(76 \%)$ heard a P.A. After the P.A. $13(57 \%)$ thought they should evacuate by exits, $6(26 \%)$ wait/look for more information, $4(17 \%)$ board a train and 1 other non-emergency related actions. More than a half, $16(57 \%)$, thought it wasn't a real emergency.

Evac.3 (minimal P.A. repeated) was more efficient. The evacuation movement of a crowd of 13 people started at the Concourse level after 1:15 min. However, at the bottom of the N/S escalators a crowd of 48 people did not move until the FB arrived to disperse them after 7:40 mins. After 10:30 mins the station was cleared under the supervision of the FB. A majority, 21 out of the 25 people interviewed $(84 \%)$ said they heard an alarm and $17(68 \%)$ a P.A. Nine $(60 \%)$ thought they should leave by exits, $4(27 \%)$ board a train and $2(13 \%)$ wait/look for more information. In this case, 14 $(56 \%)$ thought it wasn't a real emergency.

Evacs 4 and 5 were the two more efficient evacuations. In Evac.4 (Staff and directive P.A.) a P.A. message initiated the evacuation movement by a crowd of 20 at Concourse level 1:15 sec. after the alarm bell sounded. As in Evac. 2 an RCI stayed at Concourse level to prevent people from entering. A crowd of 15 users started to move at the bottom of the N/S escalators after 1:30 secs upon receiving an instruction to move to trains simultaneously from the P.A. and RCI. The station was cleared after 6:45 mins. Of the 26 interviewees in this evacuation, $24(92 \%)$ said they heard the alarm and $19(73 \%)$ the P.A.. After hearing the P.A., $15(79 \%)$ thought they should leave by exits, $3(16 \%)$ board a train and 1 engage in non-emergency related actions. Fourteen $(54 \%)$ thought it wasn't a real emergency.

The last exercise, Evac.5 ('directive' P.A.) was very quick in prompting evacuation movement by people. After the second sentence of the P.A. 'To all passengers. There is a suspected fire on the escalator between Concourse and platforms 1 and 2 ...' a crowd of 19 people started to move from the Concourse after 1:30 min. and a crowd of 16 moved after 1:00 min. at the bottom of $\mathrm{N} / \mathrm{S}$ escalator. Passengers evacuated by train as directed by the P.A. and those at Concourse level by the exits. The station was cleared after 5:45 mins except for two groups. One group was a woman with two small children and a baby in a pushchair and the other one a couple with a big pram. These two groups were evacuated by train after 7:00 and 10:15 mins respectively. Of the 22 evacuees interviewed, 18 $(82 \%)$ heard the alarm and $11(50 \%)$ heard a P.A., of which $5(50 \%)$ thought they should board a train and $5(50 \%)$ leave by exits. For the first time a majority, $13(57 \%)$ thought it was a real emergency.

\section{DISCUSSION}

The results of this study confirmed the expectation that an alarm bell only, as in Evac. 1, would be least effective in terms of the time to start to move and overall evacuation time. In fact, in Evac 1 there were still passengers in the station when the exercise was terminated almost 15 mins after the bell was set off. Although an alarm bell is supposed to mean 'evacuate the building', people seem to 'decode' or interpret this information as a system failure or a test, assuming the alarm has nothing to do with them. Users in this safety exercise simply executed their usual journey, entering the station, going down to a platform, waiting and boarding a train, or disembarking from a train, then going up to the Concourse and out via a station exit, without bothering about the ringing. Passengers getting off on platforms 1 and 2, were blocked at the bottom of N/S escalator and waited patiently for nearly 10 mins. The video recording suggests they looked slightly thwarted by the delay and the continuous ringing of the bell, but not especially anxious.

Evac. 2 was rapid in terms of the time to start to move and the overall time to evacuate. The two RCIs were eager to achieve an impressive evacuation time, as they considered this safety exercise to be a test of 'their' efficiency, rather than an exercise in monitoring the reactions of the public. In this respect, the speed of their response when the alarm began would probably have been slower if they had not been expecting a monitored exercise. As a consequence of their personal contact with 
passengers, reinforced by their uniforms symbolising authority, the station was cleared reasonably rapidly. However, three major problems arose in this evacuation. First, the PA message given out by an RCI was unclear in its delivery and content; second, passengers at the platform levels were directed by the other RCI to the Concourse level which was the most dangerous part of the station in relation to the location of the suspected fire, which was known by the RCIs when they checked the electronic board; third, staff in the station cannot be everywhere and have an overview of a situation. When the $\mathrm{RCI}$ was directing passengers off one platform, passengers were at the same time getting off a train at another platform. The lack of an overview of the situation produced a lack of coordination. Staff members had to race around trying to control the situation.

In Evac. 3 a public announcement was added to the alarm bells. Although the simple message was restricted to 'evacuate the station', it was much more effective then the alarm only in evacuating the Concourse level. However, this non-directive type of P.A. had no effect on a crowd of 48 passengers waiting at the bottom of the N/S escalators. Their familiar route to the outside was being blocked and they just waited there patiently, in the expectation that this route would eventually be cleared, or perhaps unaware that there was an alternative route to the Concourse level. The firemen posted at the top and bottom of the N/S escalators are likely to have diminished the sense of threat to passengers waiting to continue their journey or attracted to by the incident. The firemen at the bottom of the escalators reported that from time to time a user would come forward to ask, 'the P.A. says to evacuate but where?'. As the firemen were not allowed to give any information they just repeated, 'Please evacuate'.

Evac. 4 was a smooth, rapid and safe evacuation. The time to start to move was fast for the crowd gathering locations. It is important to note that RCIs in Evacs 2 and 4 started their actions the moment they heard the alarm bell compared with Evacs 3, and 5 when the first P.A. given by the Control Room was, according to the experiment procedure, more then $1 \mathrm{~min}$. after the alarm bell was set off. In Evac. 4 the Station Controllers conducted the evacuation in accordance with Metro procedures. Directive P.A.s defining the precise action to be followed were given to passengers depending on their location. The RCIs supported these instructions from the Control Room. In Evacs 4 and 5, specific P.A.s were also given to individuals such as: 'The gentleman at Concourse level should leave the station immediately. Yes, that is you next to the ticket machine'. Directive P.A.s addressed to a crowd, group of users or an individual were very effective and proved to be one of the great advantages of the Metro Control Room and communication system.

Evac. 5 was very efficient for the time and behaviour adopted. Some concern was expressed in prior discussion with senior management that an explicit P.A. reference to a threat, namely 'There is a suspected fire on $\mathrm{N} / \mathrm{S}$ escalators' might lead to 'panic'. In contrast, the statement did not encourage irrational agitated behaviour (eg people screaming or rushing around). The precise message identifying the incident and its location provoked sufficient stress to initiate an evacuation, while keeping passengers sufficiently calm to evacuate in a prompt and orderly fashion. Although the time to clear the station in Evac 5 was longer, due to the two specific groups who circumstantially arrived late, the evacuation was judged to be very successful.

\section{CONCLUSION}

It is notable that the pattern of use of the E/W escalators in Evac 2, in which passengers were sent up to the Concourse by an RCI, was strikingly similar to the pattern of movement during the King's Cross fire [11, 12]. The staffing and local P.A. system tested in Evac 2 conformed to the Fire Precautions (Sub-surface Railway Stations) Regulations 1989 produced after the King's Cross fire. This study suggests the limitations of an alarm bell, local P.A. and station staffing, in contrast to a Control Room or Centre with CCTV and directive messages through a P.A.(complemented by emergency messages on dot matrix train announcement displays on platforms). The lack of reference in the Regulations to a Control Centre communications system is considered to be a serious omission.

Without relevant information users have no way to judge and take decisions in relation to a specific situation and can easily behave in a way which seems inapporopriate to others who have 
greater knowledge of a fire spread (either at the time or in hindsight). Two factors in urgent need of attention are: how to give information to the public and what the content of this information should be. If a public announcement system is used to give information to users, it is important to ensure that the public can perceive and understand the information provided and are confident about this communication system when it is in daily use. If unreliable, contradictory information is disseminated by a P.A., it cannot be expected that people will follow the instruction given. It is essential to build up a climate of confidence through legible architecture, reliable information and building management tailored to the users.

The task for future research is to establish in detail the content of the information which is most effective in supporting people in their spatial decision making. The messages should give the public precise and timely instructions about what action is expected of them and why. In an emergency telling people the truth about an incident appears to be the best way to convince them of the gravity of a situation. A coordinated communication system is a prerequisite if a reasonably prompt and safe evacuation is to be achieved.

ACKNOWLEDGEMENTS: Mrs Proulx is a Ph.D. student at the Université de Montréal, Québec Canada. She is grateful for the financial support of the Social Sciences and Humanities Research Council of Canada. The research project was conducted in close collaboration with the Tyne and Wear Metropolitan Fire Brigade and the Tyne and Wear Passenger Transport Executive (P.T.E.) to whom the authors are indebted for their invaluable cooperation and support.

\section{REFERENCES}

1. Sime, J. D., "The concept of panic", in Fires and Human Behaviour, ed. D. Canter, pp.63-81, First edition: Chichester, Wiley, London, 1980.

2. Keating, J. P., "The myth of panic", Fire Journal, May, 57-61, 1982.

3. Sime, J. D., "Movement toward the familiar: person and place affiliation in a fire entrapment setting", Environment and Behaviour, 17:6, 697-724, 1985.

4. Sime, J. D. and Kimura, M, "The timing of escape behaviour: exit choice behaviour in fires and building evacuations", in Safety in the Built Environment, ed. J. D. Sime, pp. 48-61, London: E \& F N Spon, 1988.

5. Keating, J. P. and Loftus, E., "Vocal alarm systems for high-rise buildings - a case study", Mass Emergencies, 2, 25-34, 1977.

6. Tong, D. and Canter, D. "Informative warnings: in situ evaluations of fire alarms", Fire Safety Journal, 9, 267-279, 1985 .

7. Geyer, T., Bellamy, L., Max-Lino, R., Harrison, P., Bahrami, Z. and Modha, B,. "An evaluation of the effectiveness of the components of informative warning systems", in Safety in the Built Environment. ed. J. D. Sime, pp. 36-47, London; E \& F N Spon, 1988.

8. Proulx, G. and Sime, J. D., Appraisal of the information system in the sub-surface stations of Tyne and Wear Metro, Stage 1 of a User Safety Evaluation on behalf of Tyne and Wear Passenger Transport Executive, Newcastle upon Tyne, U.K., 1989.

9. Sime, J. D. and Proulx, G, and Kimura, M., Evacuation Safety in the Sub-surface Stations of Tyne and Wear Metro: Case study of Monument Station, Stage 2 of a User Safety Evaluation on behalf of Tyne and Wear Passenger Transport Executive, Newcastle upon Tyne, U.K., 1990.

10. Proulx, G., "Orientation spatiale dans un espace souterrain", Proceedings of the Environmental Design Research Association Conference, EDRA-18, Ottawa, pp. 68-73, 1987.

11. Fennell, D. Investigation into the King's Cross Underground Fire, Department of Transport, Her Majesty's Stationery Office, England, 1988.

12. Donald, I. and Canter, D., "How the behaviour of passengers and officials contributed to King's Cross", Fire, 1234:6, 20-22, 1989. 